\title{
Analytical Techniques for the Assay of Tulobuterol - A Review
}

\section{Bandi Chandini Ruchita and Mukthinuthalapati Mathrusri Annapurna*}

GITAM Institute of Pharmacy, GITAM (Deemed to be University), Visakhapatnam, India

*Corresponding Author: Mukthinuthalapati Mathrusri Annapurna, GITAM Institute of Pharmacy, GITAM (Deemed to be University), Visakhapatnam, India.
Received: July 28, 2021

Published: August 12, 2021

(C) All rights are reserved by Bandi Chandini Ruchita and Mukthinuthalapati Mathrusri Annapurna.

\begin{abstract}
Tulobuterol is a potent bronchodilator and chemically it is 1-(o-chloro phenyl)-2-tert-butyl amino ethanol alpha-((tert-butyl amino) methyl)-o-chloro benzyl alcohol. In comparison to other analogues Tulobuterol has a long acting effect. Various analytical techniques such as gas chromatography, high performance liquid chromatography, spectrophotometry, liquid chromatography-mass spectrometry etc. so far developed for the quantification of Tulobuterol in pharmaceutical formulations were reviewed and the significant parameters were highlighted.
\end{abstract}

Keywords: Tulobuterol; Syrup; BREMAX

\section{Introduction}

Tulobuterol $\left(\mathrm{C}_{12} \mathrm{H}_{18} \mathrm{ClNO}\right)$ is a bronchodilator and it is chemically known as 1-(o-chloro phenyl)-2-tert-butylaminoethanol alpha-((tert-butyl amino) methyl)-o-chloro benzyl alcohol. The molecular weight is 227.73 grams/mole and the pKa values are found to be 9.55 and 13.9. Tulobuterol (Figure 1) relaxes the airway muscles and makes breathing easier $[1,2]$ and it is administered by oral, inhalation and as transdermal patch. Tulobuterol is available with brand name BREMAX as tablet (Labelled claim: 1 $\mathrm{mg}$ and $2 \mathrm{mg}$ ) and also as syrup from Abbott Laboratories (India).

Ravindra Reddy., et al. developed a new UV spectrophotometric method in methanol [3] and an extractive spectrophotometric method using bromo cresol green reagent [4] for the assay of Tulobuterol in API and its pharmaceutical dosage forms where the $\lambda_{\max }$ was reported at $212 \mathrm{~nm}$ and $624 \mathrm{~nm}$ respectively. A wide range of linearity (25 - $125 \mu \mathrm{g} / \mathrm{ml}$ ) was observed while using methanol whereas a narrow range was reported while performing the vis-

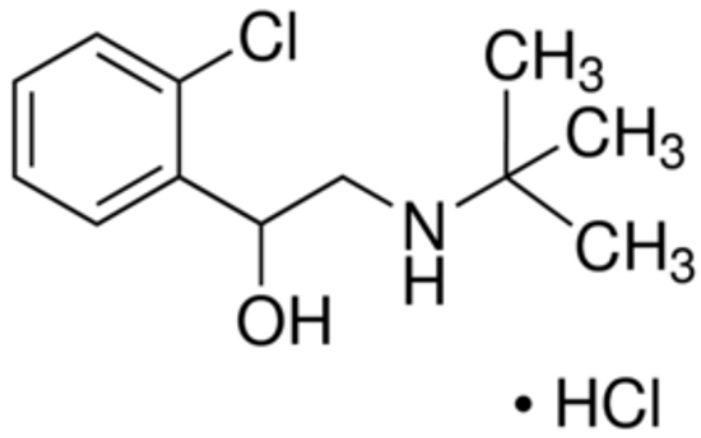

Figure 1: Chemical structure of Tulobuterol.

ible spectrophotometry using bromo cresol green reagent (0.1 - 0.8 $\mu \mathrm{g} / \mathrm{ml})$. 
Kavita Parui_and Snehalatha Boddu [5] developed a liquid chromatographic method for the determination of Tulobuterol in transdermal drug delivery system in which a mixture of acetonitrile and 0.02M Potassium dihydrogen phosphate buffer (60:40) was used as mobile phase after adjusting the $\mathrm{pH}$ to 3.0 with Ortho phosphoric acid and the linearity was observed as $25-75 \mu \mathrm{g} / \mathrm{ml}$. LIU Zhimei., et al. [6] determined Tulobuterol in Tulobuterol transdermal patch by HPLC using a mixture of methanol and sodium heptane sulfonate solution as mobile phase $(55: 45)$ in which the aqueous phase was prepared by using $\mathrm{pH} 4.0$ acetic acid and sodium acetate buffer solution and a very narrow linearity was observed as 0.005 $-0.1 \mu \mathrm{g} / \mathrm{ml}$.

Longmei Cheng., et al. quantified Tulobuterol in human plasma [7] by liquid chromatography-tandem quadrupole mass spectrometry (LC-MS/MS) in presence of an internal standard Tulobuterol-d9 using $0.1 \%$ formic acid: acetonitrile (30:70) as mobile phase in which the linearity was very narrow i.e. 0.00001-0.005 $\mu \mathrm{g} / \mathrm{ml}$. Xiao Han., et al. [8] developed a liquid chromatography-tandem mass spectrometry method (LC-MS/MS) for the determination of Tulobuterol in rat plasma in presence of an internal standard, Clenbuterol using $0.1 \%$ formic acid: water: methanol as mobile phase and the method was applied for the pharmacokinetic study of Tulobuterol patches. The linearity in this method was narrow and is found to be
$0.0005-0.1 \mu \mathrm{g} / \mathrm{ml}$. Fengguo Xu., et al. and XU Feng-Guo., et al. developed a high-performance liquid chromatography-mass spectrometry (LC-MS) for the determination of Tulobuterol using a mixture of methanol: $10 \mathrm{mM}$ ammonium acetate $(\mathrm{pH} 4.0)$ in presence of an internal standard, Clenbuterol $\mathrm{HCl}$ [9] and a mixture of methanol: $0.01 \mathrm{M}$ ammonium acetate (70:30) without internal standard [10] respectively but with the same linearity range $0.0005-0.04 \mu \mathrm{g} / \mathrm{ml}$ in rabbit's plasma.

Kugako Matsumura., et al. quantified Tulobuterol and its metabolites in human urine by mass fragmentography using chemical ionisation (Ammonia) and helium as carrier gas [11] and also in human serum by electron-capture gas-liquid chromatography using nitrogen as carrier gas in presence of an internal standard l, l-Bis- (4-fluorophenyl)-2,2 dichloro ethane [12]. Thienpont LM., et al. measured Tulobuterol by capillary gas chromatography (GC/ MS) in human plasma [13] using helium as carrier gas in presence of an internal standard, Des chloro Tulobuterol.

The analytical methods or instrumental techniques used by different authors for the quantification of Tulobuterol in pharmaceutical formulations such as tablets, transdermal patches as well as biological samples such as human plasma, human serum, human urine, rat plasma, rabbit plasma were briefly summarised in table 1.

\begin{tabular}{|c|c|c|c|}
\hline Reagent/Mobile phase (v/v) & $\begin{array}{l}\text { Linearity } \\
(\mu \mathrm{g} / \mathrm{ml})\end{array}$ & Comment & Ref \\
\hline \multicolumn{4}{|l|}{ Spectrophotometry } \\
\hline Methanol & $25-125$ & $\lambda_{\max }: 212 \mathrm{~nm}$ & [3] \\
\hline Bromo Cresol Green & $0.1-0.8$ & $\lambda_{\max }: 624 \mathrm{~nm}$ & [4] \\
\hline \multicolumn{4}{|l|}{ Liquid chromatography } \\
\hline $\begin{array}{l}\text { Acetonitrile: } 0.02 \mathrm{M} \text { Potassium dihydrogen phosphate buffer } \\
(60: 40) \mathrm{pH} \text { adjusted to } 3.0 \text { with Ortho phosphoric acid }\end{array}$ & $25-75$ & HPLC & {$[5]$} \\
\hline $\begin{array}{l}\text { Methanol: Sodium heptane sulfonate solution } \\
\text { (Prepared by pH } 4.0 \text { acetic acid-sodium acetate buffer solution) } \\
\text { (55:45) }\end{array}$ & $0.005-0.1$ & $\begin{array}{c}\text { HPLC } \\
\text { (Transdermal patch) }\end{array}$ & [6] \\
\hline \multicolumn{4}{|l|}{ Liquid chromatography-Mass spectroscopy } \\
\hline $\begin{array}{l}\text { 0.1\% Formic acid: Acetonitrile (30:70) } \\
\text { Tulobuterol-d9 (Internal standard) }\end{array}$ & $0.00001-0.005$ & $\begin{array}{c}\text { LC-MS/MS } \\
\text { Human plasma }\end{array}$ & {$[7]$} \\
\hline
\end{tabular}




\begin{tabular}{|c|c|c|c|}
\hline $\begin{array}{l}0.1 \% \text { Formic acid: Water: Methanol } \\
\text { Clenbuterol (Internal standard) }\end{array}$ & $0.0005-0.1$ & $\begin{array}{l}\text { LC-MS/MS } \\
\text { Rat plasma }\end{array}$ & [8] \\
\hline $\begin{array}{l}\text { Methanol: } 10 \text { mM Ammonium acetate (pH 4.0) } \\
\text { Clenbuterol HCl (Internal standard) }\end{array}$ & $0.0005-0.04$ & $\begin{array}{l}\text { LC-ESI-MS } \\
\text { Rabbit's plasma }\end{array}$ & {$[9]$} \\
\hline Methanol: $0.01 \mathrm{M}$ Ammonium acetate (70:30) & $0.0005-0.04$ & $\begin{array}{l}\text { LC-MS } \\
\text { Rabbit's plasma }\end{array}$ & [10] \\
\hline \multicolumn{4}{|l|}{ Gas chromatography } \\
\hline $\begin{array}{l}\text { Chemical Ionisation: Ammonia } \\
\text { Carrier gas: Helium }\end{array}$ & $0.005-0.3$ & $\begin{array}{l}\text { GC-MS } \\
\text { Human urine }\end{array}$ & [11] \\
\hline $\begin{array}{l}\text { Carrier gas: Nitrogen } \\
\text { l, l-Bis- (4-fluorophenyl)-2,2 dichloro ethane (Internal standard) }\end{array}$ & - & $\begin{array}{l}\text { Electron capture GLC } \\
\text { Human serum }\end{array}$ & [12] \\
\hline $\begin{array}{l}\text { Carrier gas: Helium } \\
\text { Des chloro Tulobuterol (Internal standard) }\end{array}$ & $0-0.0061$ & $\begin{array}{l}\text { Capillary GC/MS } \\
\text { Human plasma }\end{array}$ & [13] \\
\hline
\end{tabular}

Table 1: Review of analytical techniques.

\section{Conclusion}

The present review helps the readers to understand the existing analytical techniques developed so far for the estimation of the bronchodilator Tulobuterol and gives an overall idea about the limitations and advantages of these methods.

\section{Bibliography}

1. Uemastu T., et al. "The pharmacokinetics of the $\beta 2$ adrenoreceptors agonist, Tulobuterol, given transdermally and by inhalation". European Journal of Clinical Pharmacology 44 (1993): 361-364.

2. Fukuchi Y., et al. "Clinical efficacy and safety of transdermal tulobuterol in the treatment of stable COPD: an open-label comparison with inhaled Salmeterol". Respiratory Medicine 4.6 (2005): 447-455.

3. Ravindra Reddy Y and Krishana KVM. "Method development and validation of Tulobuterol in API and its pharmaceutical dosage forms by UV Spectrophotometry". International Journal of Pharmaceutical Sciences and Research 4.11 (2013): 42584262.

4. Ravindra Reddy Y., et al. "Extractive method development and validation of Tulobuterol in api and its pharmaceutical dosage forms by spectrophotometry". International Journal of Advances in Pharmaceutical Analysis 3.1 (2013): 20-23.

5. Kavita Parui and Snehalatha Boddu "Analytical method development and validation of RP-HPLC method for the determination of Tulobuterol in transdermal drug delivery system". World Journal of Pharmaceutical Research 6.5 (2017): 1148-1156.

6. LIU Zhi-mei., et al. "Determination of Tulobuterol in Tulobuterol transdermal patch by HPLC". Chinese Journal of Hospital Pharmacy 30.12 (2010): 996-999.

7. Longmei Cheng., et al. "Quantification of Tulobuterol, a selective $\beta 2$ adrenergic agonist, in human plasma by liquid chromatography-tandem quadrupole mass spectrometry". Journal of Chinese Pharmaceutical Sciences 25.7 (2016): 526-534. 
8. Xiao Han., et al. "Determination of Tulobuterol in rat plasma using a liquid chromatography-tandem mass spectrometry method and its application to a pharmacokinetic study of Tulobuterol patch". Journal of Chromatography B 1008 (2016): 108-114.

9. Fengguo Xu., et al. "High-performance liquid chromatography electrospray ionization mass spectrometry determination of Tulobuterol in rabbit's plasma". Journal of Pharmaceutical and Biomedical Analysis 37.1 (2005): 187-193.

10. XU Feng-Guo., et al. "Determination of Tulobuterol in rabbit's plasma by LC/MS and study of its pharmacokinetics". Journal of China Pharmaceutical University 36.2 (2005): 146-149.

11. Kugako Matsumura., et al. "Quantitative determination of Tulobuterol and its metabolites in human urine by mass fragmentography". Journal of Chromatography 222.1 (1981): 53-60.

12. Kugako Matsumura., et al. "Determination of Tulobuterol in human serum by electron-capture gas-liquid chromatography". Journal of Chromatography B: Biomedical Sciences and Applications 230.1 (1982): 148-153.

13. Thienpont LM., et al. "Measurement of Tulobuterol in human plasma by capillary gas chromatography and selected ion monitoring detection". Biomedical and Environmental Mass Spectrometry 14.11 (1987): 613-616.

Volume 5 Issue 9 September 2021

(C) All rights are reserved by Bandi Chandini Ruchita and Mukthinuthalapati Mathrusri Annapurna. 